\title{
A quality improvement project in a hospital in rural Nepal - improving infection control practice using the 'Plan, Do, Study, Act' (PDSA) cycle
}

\author{
Kelvin Kong, Sarah Kong \\ St George's Hospital, London, UK
}

doi: 10.3396/IJIC.v9i3.025.13

\begin{abstract}
High quality infection control practice is fundamental to the provision of safe healthcare. In countries where healthcare is less developed, this notion is less well recognised. The Plan, Do, Study, Act (PDSA) cycle is an implementation strategy used for changing healthcare practice and forms a framework for testing multiple ideas on a small scale, before implementation of change on a larger scale. Our aim was to improve infection control standards in a rural district hospital in Nepal using the PDSA cycle. Potential areas for improvement within infection control practice were first identified. Patient contacts and hand washing episodes were then recorded on the ward round in a tally chart method on the medical wards, which was deemed to reflect infection control standards. The three week intervention period included healthcare staff education and provision of alcohol gel. Data was re-collected after the intervention.
\end{abstract}

Eighteen hand cleaning episodes were observed in 134 patient contacts in the initial one week observation period, hence $13.4 \%$ of patient contacts fulfilled appropriate hand hygiene practice. In the post intervention period, 69 hand cleaning episodes were observed in 142 patient contacts, giving rise to a $48.6 \%$ success rate. The overall percentage of appropriate hand hygiene performed therefore improved 3.6 fold. Our results confirmed an improvement in the hand hygiene practice of hospital staff.

Keywords: Infection Control and Standards; Cross Infection and Prevention and Control; Developing Countries; Delivery of Health Care and Education

\author{
Corresponding Author \\ Dr. Kelvin Kong, \\ St George's Hospital, Blackshaw Road, Tooting, London, SW17 0QT, UK \\ Email: kelvkong@hotmail.com
}




\section{Background}

It is well documented by the World Health Organization and other international health groups that healthcareassociated infection (HCAI) in developing countries is a major issue for patient safety. ${ }^{1,2}$ An extensive review found that infection rates were three times higher in these countries when compared to the USA. ${ }^{3}$ Increased HCAI contribute to prolonged hospital stays, long-term disability, increased resistance of microorganisms to antimicrobial agents, additional financial burden, and excess deaths. ${ }^{1,2,3}$

The issue of HCAl is rarely addressed in low income countries as these healthcare systems are often inundated with other important issues such as poor infrastructure, understaffing, overcrowding, insufficient equipment and lack of local and national evidence-based practice guidelines. ${ }^{4}$ While the lack of funds is a perpetual problem affecting all aspects of healthcare, simple and affordable measures such as better hand hygiene can vastly improve the rates of $\mathrm{HCAl}$ and reduce costs. ${ }^{5}$

In Nepal, one of the poorest countries in the world outside Africa, ${ }^{6}$ research on infection control practice is minimal. A study conducted in the capital city, Kathmandu, on infection control knowledge, attitude and practice amongst Nepalese health care workers revealed that only $27 \%$ of staff participating had received infection control training. ${ }^{7}$ Given that this study was conducted in Kathmandu, and the stark contrast between healthcare resources in Kathmandu compared to rural areas, it seems reasonable to assume that infection control knowledge and practice may be further lacking in resource-poor rural Nepal.

Implementing strategic change into established healthcare systems can be challenging. It is not enough to provide the tools and expect success; ongoing evaluation of the changes implemented is required. As a result, various tools have been designed for this purpose, including the Plan, Do, Study, Act (PDSA) cycle. ${ }^{8}$ The PDSA cycle has been widely documented $d^{9,10}$ and successfully used internationally in quality improvement projects for many years ${ }^{11,12}$ including infection control analysis. ${ }^{13}$
The testing cycles of the PDSA strategy form a framework for testing multiple ideas on a small scale, before the formal implementation of change on a larger scale, leading to improvement. The three main steps embedded in the PDSA cycles are:

1. Setting a clear objective

2. Collecting data and starting the analysis to determine progress

3. By evaluating the data, further testing cycles can be planned before implementation of change

\section{Methods and Results - 'Plan, Do, Study, Act'}

\section{Setting}

Gulmi District Hospital in Tamghas, Nepal, where the project was undertaken, is the only hospital to serve a population of over $340,000 .{ }^{14}$ Staffed by locally trained doctors and nurses, as well as charity funded doctors and visiting volunteers from overseas, the hospital comprises two medical wards (adults and paediatrics), an operating theatre, an emergency room, a maternity unit, and an busy outpatient department. In 2010, there were 2,017 patient discharges from the hospital. ${ }^{14}$

The participants in the project were 22 locally trained doctors and nurses working at Gulmi District Hospital at the time. The project was undertaken between $17^{\text {th }}$ July and $20^{\text {th }}$ August 2011.

\section{'Plan'}

A period of observation of infection control practice at the hospital took place and identified that hand washing practice was poor, bed linen was infrequently changed and patients with diarrhoea and respiratory tuberculosis were not isolated. There were no formal infection control guidelines in the hospital. To demonstrate the relevance and importance of infection control practice at the hospital, a survey was conducted revealing $60 \%$ of patients were admitted over a one week period with a presumed diagnosis of infectious disease that could be transmitted by contact, droplets, or the airborne route (Figure 1). The presumed diagnoses of the patients were based on history and clinical examination only since a routine microbiology laboratory service was not available at the hospital. 


\section{Percentage (\%) of patients in terms of total number of patients $x$ time spent in the ward}

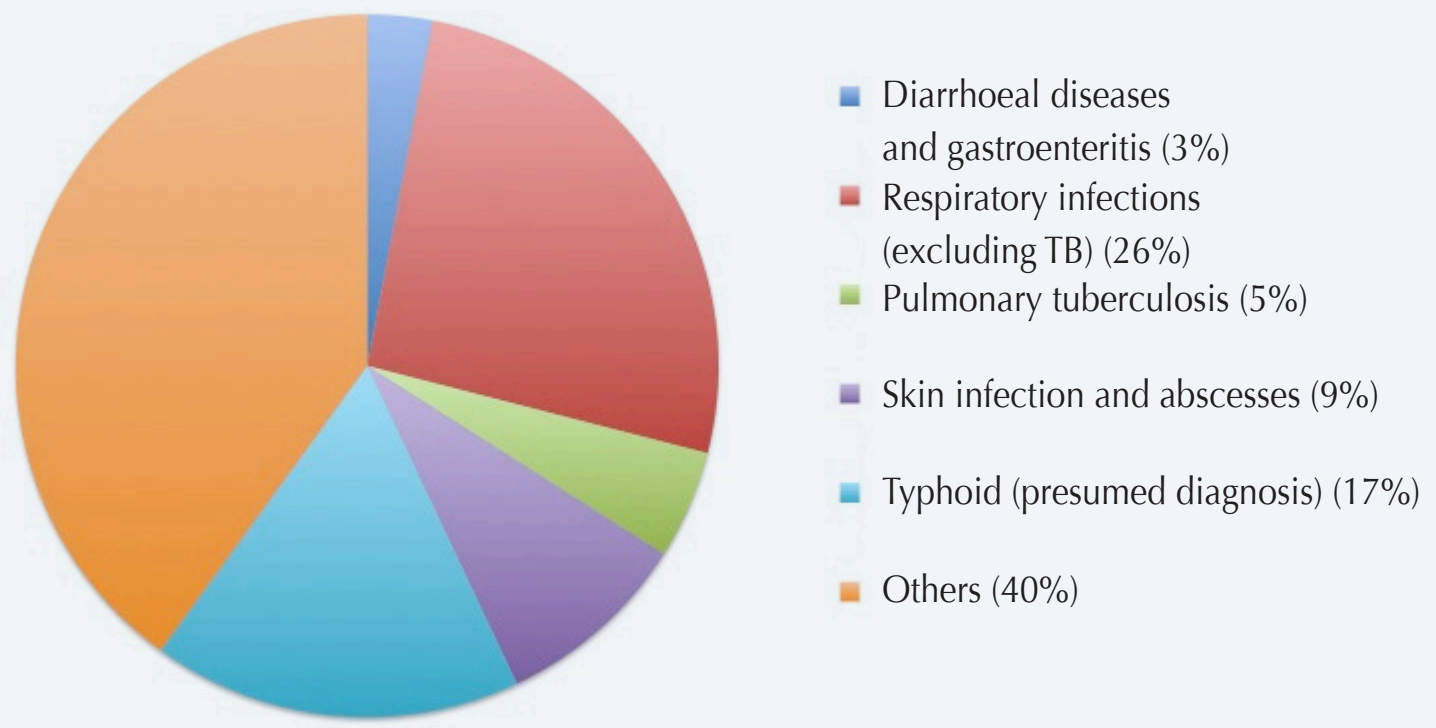

Figure 1. Presumed clinical diagnoses of patients being admitted to the medical wards during week 17th - 23rd July 2011

Table I. Major differences between standard recommendation from UK guidelines and the improvised version for Gulmi District Hospital, Tamghas, Nepal

\begin{tabular}{|c|c|c|}
\hline & $\begin{array}{l}\text { UK Guidelines Standards } \\
\text { Recommendations }\end{array}$ & Nepal Guidelines Recommendations \\
\hline & & Isolation Room not available \\
\hline Diarrhoea & Isolation Room & $\begin{array}{l}\text { Therefore cohorting is recommended with at least one } \\
\text { meter between patients in a designated area created by } \\
\text { partitions }\end{array}$ \\
\hline \multirow[b]{3}{*}{$\begin{array}{l}\text { Suspected } \\
\text { Tuberculosis (TB) }\end{array}$} & \multirow[b]{3}{*}{ Isolation Room } & Isolation Room not available \\
\hline & & Cohorting is not effective as TB is an airborne disease \\
\hline & & $\begin{array}{l}\text { Therefore advise patients to wear masks* and to } \\
\text { position away from vulnerable individuals, including } \\
\text { infants and pregnant women }\end{array}$ \\
\hline \multirow{2}{*}{$\begin{array}{l}\text { Personal Protective } \\
\text { Equipment (PPE) }\end{array}$} & \multirow{2}{*}{$\begin{array}{l}\text { Gloves and apron are put on and } \\
\text { removed immediately after and before } \\
\text { every contact with patients with } \\
\text { diarrhoea or TB }\end{array}$} & Disposable gloves and aprons not available \\
\hline & & Therefore emphasis on hand hygiene \\
\hline
\end{tabular}

* Green cotton surgical masks were worn by patients and washed after being used by an individual patient. Staff did not wear any masks, as no disposable micron mask or particulate respirators were available, and simple surgical masks did not offer any effective protection but might give the wearer a false sense of security. 


\section{Table II. Percentage of patient contacts that fulfilled appropriate hand hygiene pre- and post-intervention (from 17th to 23rd July 2011 and from 14th to 20th August 2011)}

\begin{tabular}{|c|c|c|c|c|c|c|}
\hline \multirow[t]{2}{*}{ Day of the week } & \multicolumn{2}{|c|}{ Number of patient contacts } & \multicolumn{2}{|c|}{$\begin{array}{l}\text { Number of hand } \\
\text { cleaning episodes }\end{array}$} & \multicolumn{2}{|c|}{$\begin{array}{l}\text { Percentage }(\%) \text { of patient } \\
\text { contacts that fulfilled } \\
\text { appropriate hand hygiene }\end{array}$} \\
\hline & Pre- & Post- & Pre- & Post- & Pre- & Post- \\
\hline Sunday & 22 & 24 & 3 & 12 & 13.6 & 50.0 \\
\hline Monday & 21 & 29 & 0 & 13 & 0.0 & 44.8 \\
\hline Tuesday & 22 & 24 & 12 & 16 & 54.5 & 66.7 \\
\hline Wednesday & 23 & 18 & 0 & 9 & 0.0 & 50.0 \\
\hline Thursday & 17 & 13 & 1 & 6 & 5.9 & 46.2 \\
\hline Friday & 15 & 18 & 1 & 8 & 6.7 & 44.4 \\
\hline$\underline{\text { Saturday }}$ & 14 & 16 & 1 & 5 & 7.1 & 31.2 \\
\hline Overall & 134 & 142 & 18 & 69 & 13.4 & 48.6 \\
\hline
\end{tabular}

Following the above observations, the objectives, in accordance with the PDSA cycle, were set:

1. Identify areas within infection control practice which could be improved, in particular where improvement would be feasible and sustainable.

2. Analyse whether the changes implemented are effective in improving infection control practice.

3. Achieve sustainable improvement in infection control practice at Gulmi District Hospital.

\section{'Do'}

Many $\mathrm{HCAl}$ are preventable through hand hygiene compliance, the key being cleaning hands at the right times and in the right way. ${ }^{5}$ Hand hygiene is relatively inexpensive and, when compared with many other infection prevention and control activities, is straightforward..$^{15}$ Improving hand hygiene would be a simple, affordable and sustainable approach to improving infection control practice.

The following interventions for improving hand hygiene at the hospital were carried out over a three week period:

a. An educational presentation was designed and held on infection control principles, advocating the importance of hand hygiene, and introducing the idea of 'infection control champions'. Some nurses who were unable to attend the presentation were later targeted and informed about the importance of hand hygiene.

b. Posters, consisting of simple clear diagrams and text reiterating the importance of hand hygiene, were printed and placed in the hospital ward areas and the nursing station.

c. Prior to the intervention, only one local doctor possessed a small bottle of alcohol gel that was used occasionally. Therefore, a supply of alcohol gel was bought from the local stores for the purpose of the project. Some of the local doctors had already started making their own alcoholbased hand cleaning solution prior to our arrival.

d. Alcohol hand gel was taken on ward rounds and offered to all staff making physical contact with patients. Towards the end of the three week intervention period the nurses were encouraged to offer alcohol gel to staff, thereby fulfilling the role of 'infection control champion'.

Finally, a set of infection control guidelines was developed for the hospital after consultation with the local hospital staff. While these were loosely adapted from standards within UK hospitals, they took into account the level of resources available in rural Nepal (Table I).

\section{'Study'}

To assess for any change in hand hygiene practice, an audit was undertaken. Since there was no 


\section{Overall percentage (\%) \\ of appropriate hand hygiene \\ performed before intervention}

$-13.4 \%$

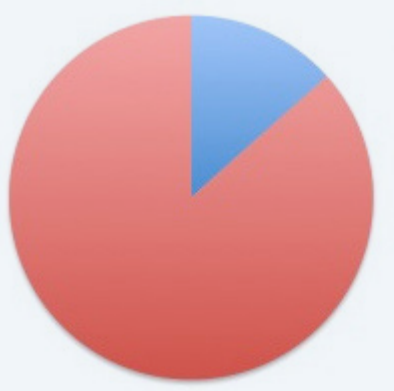

- Hand hygiene

performed

Hand hygiene

not performed

\section{Overall percentage (\%) \\ of appropriate hand hygiene \\ performed post intervention -}

$48.6 \%$

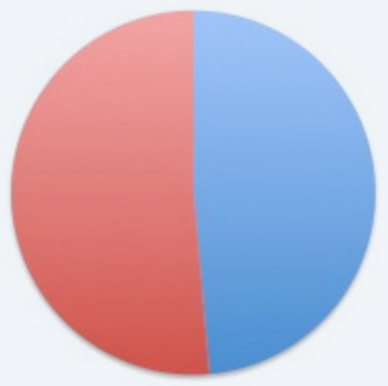

- Hand hygiene

performed

Hand hygiene

not performed

Figure 2. A 3.6 fold improvement in hand hygiene following intervention

microbiology laboratory service available at Gulmi District Hospital, it was not possible to study the rate of HCAI. Hand hygiene practice is a measurable entity and was therefore used to assess change in practice. Hand hygiene during the ward rounds was monitored; a higher percentage of hand hygiene episodes was deemed to reflect better infection control practice.

During the period over which hand hygiene practice was monitored, no verbal or physical prompting was given to staff. All patient contacts and hand hygiene episodes were recorded on the ward round in a tally chart method on the two in-patient medical wards. Hand hygiene was deemed sufficient if carried out before patient contact, using either, soap and water, or alcohol based hand rub. Patient contact was classed as contact with the patient's skin or clothes. Although the WHO recommends hand hygiene be carried out if entering the patient's surroundings, ${ }^{5}$ this proved impractical in this set up due to the close proximity of patient beds in the hospital.

Prior to our interventions to improve hand hygiene, 134 patient contacts were monitored in the one week period from $17^{\text {th }}$ to $23^{\text {rd }}$ July 2011, with 18 hand cleaning episodes observed, leading to $13.4 \%$ of patient contacts fulfilling appropriate hand hygiene practice (Table II).

In the post intervention period, 142 patient contacts were monitored in the one week period from $14^{\text {th }}$ to $20^{\text {th }}$ August 2011, with 69 hand cleaning episodes observed, giving rise to $48.6 \%$ of patient contacts that fulfilled appropriate hand hygiene (Table II). The overall percentage of appropriate hand hygiene performed therefore improved 3.6 fold (Figure 2).

\section{'Act'}

From the results of the initial hand hygiene survey, it was clear that there was considerable room for improvement in the hand hygiene rates. After the intervention, there was indeed significant improvement in hand hygiene even though it still fell short of international standards - most UK institutions have hand hygiene rates of above $90 \% .{ }^{16}$ Nonetheless, the stark improvement in the first weeks post intervention was promising.

With the lack of resources, attempts to isolate patients were impractical and efforts were directed on improving hand hygiene first, rather than other areas of the infection control guidelines.

During the ten weeks at Gulmi District Hospital, we were unable to engage in more PDSA cycles. However, we presented our findings to the local doctors and authorities, with the aim that further volunteers to the hospital will continue our work. The results of this audit and our recommendations were propagated within the charity organisation supporting Gulmi District Hospital (Rural Assistance Nepal), in the hope that other hospitals supported by the same 
charity may be encouraged to improve their infection control practice, and hence the quality of patient care, in a similar manner.

\section{Discussion}

Through the use of the PDSA cycle, it has been identified that low resource interventions can be an effective way to improve hand hygiene practice. In our audit, appropriate hand hygiene episodes undertaken by the healthcare workers during ward rounds improved 3.6 fold from $13.4 \%$ to $48.6 \%$ and, a sense of greater awareness of the importance of hand hygiene has been reported from other areas of the hospital, such as the outpatient department.

With the introduction of the infection control guidelines we compiled, there were some areas of resistance to changing practice amongst the hospital staff, and, there were other barriers to the implementation of the guidelines. For example, often there were more patients than beds, resulting in patients lying on temporary wooden beds on the floor. In view of this lack of resources, advice on isolating patients was impractical.

There are several limitations of our work. Firstly, following the interventions, there was awareness amongst the staff that they were being observed and therefore an increase in hand hygiene compliance may have occurred solely for this reason. This observation bias, known as the Hawthorne effect, ${ }^{17}$ is commonly reported in studies aiming to increase hand hygiene compliance although it remains unclear how much this can impact on the end results of hand hygiene auditing. ${ }^{18}$ Methods to overcome this bias are reported, ${ }^{19}$ but these are often costly and not practical for use in a developing country. Importantly, although observation bias likely led to apparently better hand hygiene practice, our presence may have served as a reminder on the importance of hand hygiene and was ultimately beneficial.

Secondly, we assessed hand hygiene practice during ward rounds only. We chose to monitor at the morning ward rounds since this was the main daily gathering of hospital staff and we made the assumption that this would be representative of hospital-wide compliance.
Additionally, there was only a short period of observation and intervention in the project, due to our limited time in Nepal. We therefore cannot comment on the sustainability of our intervention; we certainly cannot presume that long term improvement in hand hygiene behaviour, or compliance with the improvised guidelines, will have been achieved through our very short term project. To achieve long term changes, we believe that incorporating infection control teaching into the main educational programme of local healthcare professionals, as well as conducting regular audit cycles, would be helpful.

Finally, we did not assess the efficacy of hand hygiene and looked only at the incidence of hand hygiene episodes. The technique of hand hygiene undertaken by healthcare staff is crucial in achieving proper decontamination of the hands and has been widely studied. ${ }^{5,20}$ Again, a lack of resources in this setting makes monitoring efficacy of hand hygiene a challenge. We viewed that any increase in the compliance of hand hygiene would be a notable and worthwhile improvement from previous behaviour.

Improving infection control practice alone cannot solve the overriding fundamental issues affecting healthcare in developing countries such as poor infrastructure, lack of funds and lack of equipment; to achieve such changes would entail projects on a much larger scale. However, small scale studies and interventions, from willing individuals, can still be beneficial.

\section{Acknowledgements}

We would like to thank the staff of Gulmi District Hospital, Tamghas, Nepal, for their participation in the project. In particular, we would like to thank Dr Kashim Shah, Clinical Co-coordinator, and Dr Tribuvan Jha, Medical Education Coordinator, for their encouragement and support.

Additionally, we would like to thank Marianne Heredge, Project Director at UK registered charity Rural Assistance Nepal (Reg. No. 1124311), without whom we would not have had the opportunity to spend time at Gulmi District Hospital.

Finally, thank you to James Chan for his guidance in the compilation of this article. 


\section{References}

1. Burke J. P. Infection control - a problem for patient safety. $N$ Engl / Med 2003; 348: 651-656. http://dx.doi.org/10.1056/ NEJMhpr020557

2. Report on the burden of health care-associated infection worldwide. Clean Care is Safer Care. Geneva: World Health Organization, 2011. http://whqlibdoc.who.int/ publications/2011/9789241501507_eng.pdf [Last accessed 17th November 2012]

3. Allegranzi B, Bagheri Nejad S, Combescure C, et al. Burden of endemic health-care-associated infection in developing countries: systematic review and meta-analysis. Lancet 2010; 377(9761): 228 - 241. http://dx.doi.org/10.1016/S01406736(10)61458-4

4. Bagheri Nejad S, Allegranzi B, Syed SB, Ellis B, Pittet D. Health-care-associated infection in Africa: a systematic review. Bull World Health Organ 2011; 89: 757-765. http:// dx.doi.org/10.2471/BLT.11.088179

5. WHO Guidelines on Hand Hygiene in Health Care. First Global Patient Safety Challenge. Clean Care is Safer Care. Geneva: World Health Organization, 2009. http://whqlibdoc. who.int/publications/2009/9789241597906_eng.pdf [Last accessed 17th November 2012]

6. World Bank List of Economies. Washington, DC: The World Bank, 2011.

7. Paudyal P, Simkhada P, Bruce J. Infection control knowledge, attitude, and practice among Nepalese health care workers. Am J Infect Control 2008; 36(8): 595-597. http://dx.doi. org/10.1016/j.ajic.2007.10.026

8. Langley GL, Nolan KM, Nolan TW, Norman CL, Provost LP. The Improvement Guide: A Practical Approach to Enhancing Organizational Performance. 2nd Ed. San Francisco: Jossey Bass, 2009.

9. Berwick DM. Organisational matters: Improvement, trust, and the healthcare workforce. Qual Saf Health Care 2003; 12: 448-452. http://dx.doi.org/10.1136/qhc.12.6.448

10. Stevenson KB, Loeb M. Performance improvement in the long-term-care setting: Building on a foundation of infection control. Infect Control Hosp Epidemiol 2004; 25(1): 72-79. http://dx.doi.org/10.1086/502296

11. Guinane CS, Sikes Jl, Wilson RK. Using the PDSA cycle to standardize a quality assurance program in a quality improvement-driven environment. It Comm I Qual Improv 1994; 20(12): 696-705.
12. Lipshutz AKM, Fee C, Schell H, et al. Strategies for success: A PDSA analysis of three QI initiatives in critical care. Jt Comm I Qual Patient Saf 2008; 34(8): 435-444.

13. Van Tiel FH, Elenbaas TWO, Voskuilen BMAM, et al. Plando-study-act cycles as an instrument for improvement of compliance with infection control measures in care of patients after cardiothoracic surgery. I Hosp Infect 2006; 62(1): 64-70. http://dx.doi.org/10.1016/j.jhin.2005.05.016

14. Ministry of Health and Population, Department of Health Services, Western Regional Health Directorate, District Health Office, Gulmi, Nepal. Health Services Coverage Fact Sheet. Gulmi: Government of Nepal, 2011.

15. Gould D. Auditing hand hygiene practice. Nurs Stand 2010; 25(2): 50-56.

16. NHS National Services Scotland. National Hand Hygiene NHS Campaign. Compliance with Hand Hygiene - Audit Report. Edinburgh: Health Protection Scotland, 2007. http:// www.documents.hps.scot.nhs.uk/hai/infection-control/ national-hand-hygiene-campaign/audit-report.pdf [Last accessed 11th July 2012]

17. Maury E, Moussa N, Lakermi C, Barbut F, Offenstadt G. Compliance of health care workers to hand hygiene: awareness of being observed is important. Intensive Care Med 2006; 32(12): 2088-2089. http://dx.doi.org/10.1007/ s00134-006-0398-9

18. Erasmus V, Daha TJ, Brug $\mathrm{H}$, et al. Systematic Review of Studies on Compliance with Hand Hygiene Guidelines in Hospital Care. Infect Control Hosp Epidemiol 2010; 31(3): 283-294. http://dx.doi.org/10.1086/650451

19. Sahud AG, Bhanot N, Radhakrishnan A, Bajwa R, Manyam $\mathrm{H}$, Post JC. An electronic hand hygiene surveillance device: a pilot study exploring surrogate markers for hand hygiene compliance. Infect Control Hosp Epidemiol 2010; 31(6): 634-639. http://dx.doi.org/10.1086/652527

20. Fishbein AB, Tellez I, Lin H, Sullivan C, Groll ME. Glow gel hand washing in the waiting room: a novel approach to improving hand hygiene education. Infect Control Hosp Epidemiol 2011; 32(7): 661-666. http://dx.doi. org/10.1086/660359 